\title{
INVESTIGATION OF CHRONIC PULMONARY THROMBOEMBOLISM AND FACTORS ASSOCIATED IN SYSTEMIC LUPUS ERYTHEMATOSUS
}

FLAVIA LUIZA MARIN (UNESP-BOTUCATU, SAO PAULO, SP, Brasil), SILMEIA GARCIA ZANATI BAZAN (UNESP, Botucatu, SP, Brasil), KARINA NOGUEIRA DIAS SECCO MALAGUTTE (UNESP, BOTUCATU, SP, Brasil), SONIA MARTA MORIGUGHI (UNESP, BOTUCATU, SP, Brasil), KATIA HIROMOTO KOGA (UNESP, BOTUCATU, SP, Brasil), SERGIO MARRONE RIBEIRO (UNESP, BOTUCATU, SP, Brasil), LUIS CUADRADO MARTIN (UNESP, BOTUCATU, SP, Brasil), HUGO HYUNG BOK YOO (UNESP, BOTUCATU, SP, Brasil)

\section{BACKGROUND}

Systemic lupus erythematosus (SLE) and pulmonary embolism (PE) have a large variety of clinical manifestations, including being asymptomatic. The literature mostly comes from medical records, death certificates and autopsies, with different inclusion criteria, producing underestimated and discrepant results. The global incidence of PE in the general population is $0.2-0.8 / 1000$ and the prevalence is $0.7 \%$. However, SLE is a risk factor to PE and the prevalence is poorly studied. USA estimates this prevalence in $1.62 \%$ and it is still unknown in chronic PE. The aim of this study is to evaluate the prevalence of PE, specifically chronic PE and factors associated in SLE.

\section{MATERIALS AND METHODS}

Observational prospective study from March 2018 to May 2019, in a cohort of 226 SLE patients diagnosed at the Rheumatology Department in UNESP-Botucatu/SP. Consecutive patients were evaluated and data were obtained in electronic medical records from 2012. Inclusion criteria: over 18 years, SLE by ACR and / or SLICC criteria and consent form signed; exclusion criteria: other serious diseases, pregnant women, drug addiction, systemic sclerosis and antiphospholipid syndrome. Those with little or no findings in X-ray should perform perfusion lung scintigraphy, the remainder undergo CT pulmonary angiography.

\section{RESULTS}

164 patients were included, 47 (28.6\%) presented PE. Of those 14 (29.7\%) being acute PE diagnosed by CT pulmonary angiography and 33 (70.3\%) chronic PE diagnosed by pulmonary scintigraphy. 41 patients underwent perfusion lung scintigraphy and $33(80.5 \%)$ resulted in perfusion defects suggestive of chronic PE. The statistical analysis was performed in this last group subdivided into 2 , with cutoff point of $10 \%$ in the perfusion defects. There were $95,1 \%$ of women with a mean age of $42 \pm 13.7$ years and thrombocythemia was associated with the outcome even after adjusting for confounding variables ( $p<$ 0.05). There was no influence on the presence or titers of antiphospholipid antibodies.

\section{CONCLUSION}

SLE is a high risk factor for PE and its total prevalence in this study is $28.6 \%$, as it included acute PE (28.6\%) and chronic PE (70,3\%). We draw attention to the thrombocythemia associated with the perfusion defects and we suggest a prospective clinical trial evaluating prognostic efficacy with the use of acetylsalicylic acid, oral anticoagulant or clinical follow-up. 